\title{
EDITORIAL
}

\section{Globalización, delitos transnacionales y las herramientas de la ciencia}

La globalización, la sobrepoblación y los delitos transnacionales son algunos de los fenómenos que invitan a seguir en la búsqueda de mecanismos y fórmulas que permitan avanzar en el logro de resultados positivos en la seguridad que afecta al ser humano en todas sus aristas llámese seguridad humana, seguridad informática, ambiental e inclusive la seguridad alimenticia. Es por lo anterior que invitamos a que se adentren en el mundo de la investigación científica, que es la que ha permitido al ser humano un pensamiento crítico que conlleva al descubrimiento de herramientas que han permitido mejorar la calidad de vida, pero que también son de gran preocupación y que no pueden quedar estáticas, así como algunos de nuestros antepasados que en su afán de descubrir nos han llevado a la tecnología que hoy en día nos acompaña. Así se debe seguir investigando para fortalecer los procesos de hoy y asegurar la supervivencia del ser humano en un futuro.

Brigadier General MIREYA CORDON LÓPEZ

Directora Nacional de Escuelas 